\title{
SOCIODEMOGRAPHIC FACTORS AFFECTING PATIENT COMPLIANCE TO LONG-TERM THERAPIES
}

\author{
SHAKEEL AHMAD MIR* \\ Department of Clinical Pharmacology, Sher-I-Kashmir Institute of Medical Sciences, Srinagar, Kashmir, India. \\ Email: drshakeelahmadmir@gmail.com
}

Received: 17 April 2021, Revised and Accepted: 25 May 2021

\section{ABSTRACT}

Objective: The aim is to study the effect of various sociodemographic factors on patient compliance in long-term therapies.

Methods: This is a questionnaire-based study of 195 adult outdoor patients suffering from chronic illnesses and receiving long-term drug therapy. Various sociodemographic factors were noted in a validated questionnaire. Questions about drugs being taken were asked. The compliance was measured by General Medication Adherence Scale.

Results: The study population consists of $51.3 \%$ of males and $48.7 \%$ of females. About $39.0 \%$ of participants were literate and $61.0 \%$ were illiterate. About $72.3 \%$ belonged to the rural area, $13.3 \%$ urban, and $14.4 \%$ to the main city. About 33.3\% were self-employed or unemployed, $17.4 \%$ government employees, and $49.3 \%$ were private employees. About $20.0 \%$ belonged to high-income group, and $40.0 \%$ to middle- and $40.0 \%$ to low-income group. Statistically significant correlation was found between compliance and age, gender, area of residence, education, and marital status ( $<<0.05$ ). Better compliance was observed in men, unmarried,middle-aged, literate, and urban populations.

Conclusions: We conclude that some sociodemographic factors correlate with compliance to long-term therapies.

Keywords: Sociodemographic, Compliance, Long-term therapy, Chronic disease.

(C) 2021 The Authors. Published by Innovare Academic Sciences Pvt Ltd. This is an open access article under the CC BY license (http://creativecommons.org/ licenses/by/4.0/) DOI: http://dx.doi.org/10.22159/ajpcr.2021v14i7.41868. Journal homepage: https://innovareacademics.in/journals/index.php/ajpcr

\section{INTRODUCTION}

The main aim of the prescribed therapy is to achieve the desired results in the patients. However, such results cannot be achieved if the patients are non-compliant [1]. Compliance is defined as the extent to which a person's behavior (in terms of taking medications, following diets, or executing lifestyle changes) coincides with medical or health advice [2]. Non-compliance can be described as failing to enroll in a treatment program, terminating treatment early, or failing to follow orders, including those related to medication administration [3].

Non-compliance can be divided into primary (not buying or receiving the medicines) and secondary (not complying with the instructions regarding dosage, frequency, and duration of medication intake). The phrases compliance and non-compliance are clinician oriented. The words adherence and non-adherence have been proposed to change the focus to patients. In clinical practice, however, these words are interchangeable [4].

According to the $\mathrm{WHO}$, the factors influencing compliance to treatment may be classified into five categories such as patient-centered factors (sociodemographic factors, health belief, health literacy, forgetfulness, etc.), therapy-related factors (complexity of the medical regimen, duration of treatment, side effects, etc.), health-care system factors (poorly developed health services, non-existent reimbursement, patient-physician relationship, etc.), social and economic factors (poor socioeconomic status, poverty, unemployment, lack of effective social support networks, etc.), and disease factors (severity of symptoms, level of disability, comorbidity, and complications) [5].

Poor therapeutic compliance jeopardizes patient care efficacy, making this a crucial problem in population health from both a quality of life and a health economics standpoint [6].
Therapeutic non-compliance is associated with excess emergency hospital visits, hospitalizations, and higher treatment costs. It causes loss of productivity and has a negative impact on patient's quality of life [1].

It has been estimated that the compliance to short-term therapy is $70-80 \%$ and long-term therapy $40-50 \%$. Good compliance is defined as taking $80-120 \%$ of the medications prescribed [7].

The influence of various sociodemographic factors on compliance is less clear cut.

Various studies have obtained conflicting results while studying association of compliance to sociodemographic factors. The present study also aims to find a relationship between various sociodemographic factors and compliance.

\section{METHODS}

Data were collected from the outpatient department of SKIMS Hospital, Srinagar, Kashmir, from December 2020 to March 2021. The nature of the study was explained to patients and their relatives and written consent was taken from all subjects. The information was kept confidential. Data were collected by interview method using a pre-designed, validated, pre-tested questionnaire. All the relevant sociodemographic factors were recorded in the pro forma. 250 patients were given the questionnaire. only 195 returned the completely filled questionnaire.

\section{Inclusions criteria}

Age more than 18 years, suffering from documented chronic disease, taking prescribed drugs for past 6 months, ability to communicate by at least one of the means, namely, speaking or writing, those willing to participate in the study. 


\section{Exclusion criteria}

Age less than 18 years suffering from an acute disease, on short-term drug therapy, inability to communicate by at least one of the means, namely, speaking or writing, those not willing to participate in the study.

\section{Study tools}

Validated demographics questionnaire was prepared in English and Urdu. Section one had the questions about the general demographic information such as gender, age, place of residence, qualification, occupation, economic status, and marital status. Section two asked the questions related to medication being taken. To assess therapeutic compliance, we used the English and Urdu versions of a novel medication adherence tool known as General Medication Adherence Scale (GMAS) after obtaining permission from the authors of the scale.

\section{Data entry, analysis, and interpretation}

Data were entered into a computer, and analysis was done by a combination of manual calculators and online VassarStats. Descriptive and inferential statistics were used appropriately.

\section{RESULTS}

Table 1 shows that the study population consists of $51.3 \%(n=100)$ males and $48.7 \%(n=95)$ females. Table 2 shows that $0.5 \%(n=1)$ were up to 20 years old, $8.7 \%(n=17)$ were $21-30$ years, $13.3 \%(n=26)$ $31-40$ years, $16.9 \%(n=33) 41-50$ years, $23.1 \%(n=45) 51-60$ years, $24.1 \%(n=47) 61-70$ years, and $13.3 \%(n=26)$ were above 70 years. Table 3 shows $39.0 \%(n=76)$ were literate and $61.0 \%(n=119)$ were illiterate. Table 4 shows that $97.0 \%(n=189)$ were married and $3.0 \%$ $(n=3)$ were unmarried. Table 5 shows that $72.3 \%(n=141)$ belonged to rural area, $13.3 \%(\mathrm{n}=26)$ urban, and $14.4 \%(\mathrm{n}=28)$ to main city. Table 6 shows that $33.3 \%(n=65)$ were self-employed, $17.4 \%(n=34)$ govt. employees, and $49.3 \%(n=96)$ were private employees. Table 7 shows that $20.0 \%$ belonged to high-income group, and $40.0 \%(n=78)$ to middle- and $40.0 \%(n=78)$ to low-income group. Table 8 shows that $8.0 \%(n=8)$ males had poor, $31.0 \%(n=31)$ low, $10.0 \%(n=10)$ partial,

Table 1: Gender

\begin{tabular}{lll}
\hline Gender & No. & \% \\
\hline Males & 100 & 51.3 \\
Females & 95 & 48.7 \\
Total & 195 & 100 \\
\hline
\end{tabular}

Table 2: Age

\begin{tabular}{lll}
\hline Age group & No. & \% \\
\hline Up to 20 years & 1 & 0.5 \\
21-30 years & 17 & 8.7 \\
31-40 years & 26 & 13.3 \\
$41-50$ years & 33 & 16.9 \\
$51-60$ years & 45 & 23.1 \\
61-70 years & 47 & 24.1 \\
>70 years & 26 & 13.3 \\
Total & 195 & 100 \\
\hline
\end{tabular}

Table 3: Education

\begin{tabular}{lll}
\hline Group & No. & \% \\
\hline Literate & 76 & 39.0 \\
Illiterate & 119 & 61.0 \\
Total & 195 & 100 \\
\hline
\end{tabular}

Table 4: Marital status

\begin{tabular}{lll}
\hline Group & No. & \% \\
\hline Married & 189 & 97.0 \\
Unmarried & 06 & 3.0 \\
Total & 195 & 100 \\
\hline
\end{tabular}

$30.0 \%(n=30)$ good, and $21.0 \%(n=21)$ high adherence to therapy. About $10.5 \%(n=10)$ of females had poor, $35.8 \%(n=34)$ low, $8.4 \%$ $(n=8)$ partial, $37.9 \%(n=36)$ good, and $7.4 \%(n=7)$ high adherence.

Those in the age group of up to 20 years, $100 \%(n=1)$ had good adherence. In age group 21-30 years, 5.9\% (n=1) had low, 23.5\% (n=4) partial, $53.0 \%(n=9)$ good, and $17.6 \%(n=3)$ high adherence. In the age group of $31-40$ years, $7.7 \%(n=2)$ had poor, $23.1 \%(n=6)$ low, $11.5 \%$ $(n=3)$ partial, 42.3\% $(n=11)$ good, and $15.4(n=4)$ high adherence. In the age group $41-50$ years, $9.1 \%(n=3)$ had low, $12.1 \%(n=4)$ partial, $57.6 \%(n=19)$ good, and $21.2 \%(n=7)$ high adherence.

In the age group of $51-60$ years, $13.3 \%(n=6)$ had poor, $46.7 \%(n=21)$ low, $4.4 \%(n=2)$ partial, $22.2 \%(n=10)$ good, and $13.3 \%(n=6)$ high adherence. In the age group of $61-70$ years, $12.8 \%(n=6)$ had poor, $42.6 \%(n=20)$ low, $4.2 \%(n=2)$ partial, $25.5 \%(n=12)$ good, and $14.9 \%(n=7)$ high adherence. In the age group of above 70 years, $3.8 \%(n=1)$ had poor, $65.4 \%(n=17)$ low, $7.7 \%(n=2)$ partial, $19.2 \%(n=5)$ good, and 3.8\% $(n=1)$ high adherence

About 1.3\% (n=1) among literates had poor, 1.3\% $(\mathrm{n}=1)$ low, $18.4 \%$ $(n=14)$ partial, 55.3\% $(n=42)$ good, and 23.7\% $(n=18)$ high adherence. About $14.3 \%(n=17)$ among illiterates had poor, $53.8 \%(n=64)$ low, $4.2 \%$ $(n=5)$ partial, 19.3\% $(n=23)$ good, and 8.4\% $(n=10)$ high adherence. About $10.6 \%(n=20)$ married persons had poor, $52.9 \%(n=100)$ low, and $36.5 \%(n=69)$ good adherence. Among unmarried persons, $16.7 \%(n=1)$ had partial, 33.3\% (n=2) good, and 50.0\% $(n=3)$ high adherence. About $5.0 \%(\mathrm{n}=7)$ among those coming from rural areas had poor, $53.9 \%$ $(\mathrm{n}=76)$ low, $5.7 \%(\mathrm{n}=8)$ partial, $24.8 \%(\mathrm{n}=35)$ good, and $10.6 \%(\mathrm{n}=15)$ high adherence. About $11.5 \%(\mathrm{n}=3)$ from urban areas had partial, $53.8 \%$ $(n=14)$ good, and $34.6 \%(n=9)$ high adherence. About $14.3 \%(n=4)$ from city had partial, 71.4\% $(n=20)$ good, and $14.3(n=4)$ high adherence. Among self-employed, 1.4\% $(n=1)$ had poor, 6.1\% $(n=4)$ low, 15.4\% $(n=10)$ partial, $46.1 \%(n=30)$ good, and 30.9\% $(n=20)$ high adherence. Those working in government sector, $17.6 \%(n=6)$ had partial, $29.4 \%$ $(n=10)$ good, and 52.9\% $(n=18)$ had high adherence. Among those working in private sector, $2.1 \%(\mathrm{n}=2)$ had poor, $10.4 \%(\mathrm{n}=10)$ low, $9.4 \%$ $(n=9)$ partial, $21.9 \%(n=21)$ good, and $56.2 \%(n=54)$ high adherence.

In high-income group, $2.6 \%(\mathrm{n}=1)$ had poor, $12.8 \%(\mathrm{n}=5)$ low, $10.2 \%$ $(n=4)$ partial, 25.6\% ( $n=10)$ good, and 48.7\% $(n=19)$ high adherence. In middle-income group, $1.3 \%(\mathrm{n}=1)$ had poor, $5.1 \%(\mathrm{n}=4)$ low, $12.8 \%$ $(n=10)$ partial, 50.0\% (n=39) good, and 30.8\% $(n=24)$ high adherence. In low-income group, 6.4\% $(\mathrm{n}=5)$ had low, $11.5 \%(\mathrm{n}=9)$ partial, $48.7 \%$ $(n=38)$ good, and $33.3 \%(n=26)$ high adherence.

Table 5: Area of residence

\begin{tabular}{lll}
\hline Group & No. & \% \\
\hline Rural & 141 & 72.3 \\
Urban & 26 & 13.3 \\
City & 28 & 14.4 \\
Total & 195 & 100 \\
\hline
\end{tabular}

Table 6: Occupation

\begin{tabular}{lll}
\hline Group & No. & \% \\
\hline Self-employed/unemployed & 65 & 33.3 \\
Govt. employee & 34 & 17.4 \\
Private sector employee & 96 & 49.3 \\
Total & 195 & 100 \\
\hline
\end{tabular}

Table 7: Economic status

\begin{tabular}{lll}
\hline Group & No. & \% \\
\hline High income & 39 & 20.0 \\
Middle income & 78 & 40.0 \\
Lower income & 78 & 40.0 \\
Total & 195 & 100 \\
\hline
\end{tabular}


Table 8: Compliance to long-term therapy

\begin{tabular}{|c|c|c|c|c|c|}
\hline \multirow[t]{2}{*}{ Group } & \multicolumn{5}{|c|}{ Compliance as per GMAS No. (\%) } \\
\hline & Poor & Low & Partial & Good & High \\
\hline \multicolumn{6}{|l|}{ Gender } \\
\hline Female & $10(10.5)$ & $34(35.8)$ & $08(8.4)$ & $36(37.9)$ & $07(7.4)$ \\
\hline Total (195) & 18 & 65 & 18 & 66 & 28 \\
\hline \multicolumn{6}{|l|}{ Age } \\
\hline $18-20$ years & $0(0.0)$ & $0(0.0)$ & $0(0.0)$ & $01(100.0)$ & $0(0.0)$ \\
\hline 21-30 years & $0(0.0)$ & $01(5.9)$ & $04(23.5)$ & $09(53.0)$ & $03(17.6)$ \\
\hline $31-40$ years & $02(7.7)$ & $06(23.1)$ & $03(11.5)$ & $11(42.3)$ & $04(15.4)$ \\
\hline $41-50$ years & $0(0.0)$ & $03(9.1)$ & $04(12.1)$ & $19(57.6)$ & $07(21.2)$ \\
\hline $51-60$ years & $06(13.3)$ & $21(46.7)$ & $02(4.4)$ & $10(22.2)$ & $06(13.3)$ \\
\hline $61-70$ years & $06(12.8)$ & $20(42.6)$ & $02(4.2)$ & $12(25.5)$ & 07 (14.9) \\
\hline$>70$ years & $01(3.8)$ & $17(65.4)$ & $02(7.7)$ & $05(19.2)$ & $01(3.8)$ \\
\hline Total (195) & 15 & 68 & 17 & 67 & 28 \\
\hline \multicolumn{6}{|l|}{ Literacy } \\
\hline Literate & $01(1.3)$ & $01(1.3)$ & $14(18.4)$ & $42(55.3)$ & 18 (23.7) \\
\hline Total (195) & 18 & 65 & 19 & 65 & 28 \\
\hline \multicolumn{6}{|l|}{ Marital status } \\
\hline Married & $20(10.6)$ & $100(52.9)$ & $0(0.0)$ & $69(36.5)$ & $0(0.0)$ \\
\hline Unmarried & $0(0.0)$ & $0(0.0)$ & $01(16.7)$ & $02(33.3)$ & $03(50.0)$ \\
\hline Total & 20 & 100 & 01 & 71 & 03 \\
\hline \multicolumn{6}{|l|}{ Residence } \\
\hline Rural & $07(5.0)$ & $76(53.9)$ & $08(5.7)$ & $35(24.8)$ & $15(10.6)$ \\
\hline Urban & $0(0.0)$ & $0(0.0)$ & $03(11.5)$ & $14(53.8)$ & 09 (34.6) \\
\hline City & $0(0.0)$ & $0(0.0)$ & $04(14.3)$ & $20(71.4)$ & 04 (14.3) \\
\hline Total & 07 & 76 & 15 & 69 & 28 \\
\hline \multicolumn{6}{|l|}{ Employment } \\
\hline Self/unemployed & $1(1.4)$ & $4(6.1)$ & $10(15.4)$ & $30(46.1)$ & $20(30.9)$ \\
\hline Govt. sector & $0(0.0)$ & $0(0.0)$ & $06(17.6)$ & $10(29.4)$ & $18(52.9)$ \\
\hline Private sector & $02(2.1)$ & $10(10.4)$ & $09(9.4)$ & $21(21.9)$ & $54(56.2)$ \\
\hline Total & 03 & 14 & 25 & 61 & 92 \\
\hline \multicolumn{6}{|l|}{ Economical } \\
\hline High income & $01(2.6)$ & $05(12.8)$ & $04(10.2)$ & $10(25.6)$ & 19 (48.7) \\
\hline Total & 02 & 14 & 23 & 87 & 69 \\
\hline
\end{tabular}

GMAS: General Medication Adherence Scale

\section{DISCUSSION}

The factors that influence compliance can be classified into patientrelated factors, therapy-related factors, healthcare system factors, socioeconomic and disease-related factors [5].

Sociodemographic variables include gender, age, area of residence, ethnicity, marital status, household, qualification, employment, and income.

The present study aims to find a relationship between various sociodemographic factors and compliance. We found a statistically significant correlation between gender and compliance $(p=0.003)$. In our study, males had better compliance as compared to females. In many studies related to this factor, contradictory results have been found. Some studies have found females patients to have better compliance [8]. We found a statistically significant correlation between age and compliance $(\mathrm{p}=0.012)$. Middle-aged patients had better compliance as compared to young and the elderly. The majority of studies conducted have found age related to compliance. Although most studies have found the elderly more compliant [1], yet some studies have found the elderly less compliant [9].

We found a statistically significant correlation between education and compliance $(p=0.000)$. Literate patients were more compliant. We did not compare the effect of various educational levels like higher or lower education on compliance. Contradictory results have been found while studying the correlation between the level of education and compliance. Some studies have found that educational level may not be a good predictor of compliance [1]. However, Rolnick et al. have found higher compliance in patients living in areas with higher education rates [10].

We found better compliance in unmarried, though in five recent studies, marital status was not found to be related to compliance [1]. Some authors believe that marriage positively affects compliance [11]. We also found an area of residence and compliance significantly correlated $(p=0.000)$. Patients belonging to the rural areas were found least compliant as compared to those from urban areas or cities. Martin et al. also found low compliance in the rural population [12].

We found no correlation between the patient occupation and compliance $(\mathrm{p}=0.292)$. We also found small but statistically significant $(\mathrm{p}=0.042)$ differences in compliance between various income groups. In some studies, income and cost of therapy were found related to compliance but in others, income was not related to compliance [1].

While socioeconomic status has not been reliably found to be an independent predictor of compliance, low socioeconomic status in developing countries can force patients to choose between competing priorities. Demands to guide the scarce resources available to meet the needs of other family members, such as children or parents for whom they care, are common examples of such priorities [5].

\section{CONCLUSIONS}

Compliance is a complex phenomenon that differs from population to population. This is a well-known problem. Non-compliance with medication is a global problem that has an effect on patient health 
outcomes and health-care costs. Several patient sociodemographic factors are linked to therapeutic non-compliance.

\section{ACKNOWLEDGMENT}

The authors would like to express their sincere thanks and gratitude to Dr. Atta Abbas Naqvi and Professor Mohamed Azmi Hassali of Discipline of Social and Administrative Pharmacy, School of Pharmaceutical Sciences, Universiti Sans Malaysia (USM), Penang, Malaysia, for allowing to use GMAS in this study. The authors also wish to thank the patients who participated in the study.

\section{AUTHORS' CONTRIBUTIONS}

All authors have made considerable contributions to the work reported in the manuscript.

\section{CONFLICTS OF INTEREST}

None.

\section{AUTHORS' FUNDING}

None.

\section{REFERENCES}

1. Jin J, Sklar GE, Oh VM, Li SC. Factors affecting therapeutic compliance: A review from the patient's perspective. Ther Clin Risk Manag 2008;4:269-86.

2. Jay S, Litt IF, Durant RH. Compliance with therapeutic regimens.
J Adolesc Health Care 1984;5:124-36.

3. Nose M, Barbui C, Gray R, Tansell M. Clinical interventions for treatment non-adherence in psychosis: Meta-analysis. Br J Psychiatry 2003;183:197-200

4. Swaminath G. You can lead a horse to the water. Indian J Psychiatry 2007;49:228-30.

5. World Health Organization. Adherence to Long-Term Therapies: Evidence for Action. Geneva: World Health Organization; 2003.

6. Joho AA. Factors affecting treatment compliance among hypertension patients in three district hospitals-Dar Es Salaam. In: Muhimbili University of Health and Allied Sciences, Dar Es Salaam Tanzania; 2012.

7. Stroupe KT, Teal EY, Weiner M, Gradus-Pizlo I, Brater DC, Murray MD. Health care and medication costs and use among older adults with heart failure. Am J Med 2004;116:443-50.

8. Chuah SY. Factors associated with poor patient compliance with antituberculosis therapy in Northwest Perak, Malaysia. Tubercle 1991;72:261-4.

9. Balbay O, Annakkaya AN, Arbak P, Bilgin C, Erbas M. Which patients are able to adhere to tuberculosis treatment? A study in a rural area in the Northwest part of Turkey. Jpn J Infect Dis 2005;58:152-8.

10. Rolnick SJ, Pawloski PA, Hedblom BD, Asche SE, Bruzek RJ. Patient characteristics associated with medication adherence. Clin Med Res 2013;11:54-65.

11. Cooper C, Carpenter I, Katona C, Schroll M, Wagner C, Fialová D, et al. The AdHOC study of older adults' adherence to medication in 11 countries. Am J Geriatr Psychiatry 2005;13:1067-76.

12. Martin MY, Kim YI, Kratt P, Litaker MS, Kohler CL, Schoenberger YM, et al. Medication adherence among rural, low-income hypertensive adults: A randomized trial of a multimedia community-based intervention. Am J Health Promot 2011;25:372-8 